\title{
Associations of Parental and Peer Characteristics with Adolescents' Social Dominance Orientation
}

Jennifer Riedl Cross

College of William and Mary, jrcross@wm.edu

Kathryn L. Fletcher

Follow this and additional works at: https://scholarworks.wm.edu/educationpubs

Part of the Gifted Education Commons

\section{Recommended Citation}

Cross, Jennifer Riedl and Fletcher, Kathryn L., Associations of Parental and Peer Characteristics with Adolescents' Social Dominance Orientation (2011). Journal of Youth and Adolescence, 40(6), 694-706. https://scholarworks.wm.edu/educationpubs/136 
Running head: ADOLESCENT SDO

Associations of Parental and Peer Characteristics with Adolescents' Social

\section{Dominance Orientation}

Jennifer Riedl Cross

William \& Mary

Kathryn L. Fletcher

Ball State University

\section{Final version accepted for publication}

Cross, J. R., \& Fletcher, K. L. (2010). Associations of parental and peer characteristics with adolescents' social dominance orientation. Journal of Youth and Adolescence. 40, 694-706. doi: 10.1007/s10964-010-9585-7 


\begin{abstract}
Studies with adults of social dominance orientation (SDO), a preference for inequality among social groups, have found correlations with various prejudices and support for discriminatory practices. This study explores the construct among adolescents at an age when they are beginning to recognize the social groups in their environment, particularly adolescent crowds. The relationship of SDO and perceptions of parents' responsiveness and demandingness were also investigated. Subjects were in grades $9-12(N=516,53 \%$ female, 96\% White). Mother's and father's responsiveness significantly predicted adolescent's SDO scores, with greater perceived responsiveness associated with lower SDO. To analyze the multiple crowd memberships of the $76 \%$ belonging to more than one crowd, two-step cluster analysis was used to identify patterns, resulting in 8 clusters of distinct, heterogeneous composition. SDO differed significantly among males in different clusters, but not females. The importance of membership was positively associated with SDO among high-status crowds and negatively associated with SDO among the academic and normal crowds. The findings have implications for prejudices that may be developing in adolescence and indicate a need for further research into the social context of SDO and its development.
\end{abstract}




\section{Associations of Parental and Peer Characteristics with Adolescents' Social Dominance Orientation}

Adolescence is an important developmental period for self-discovery. During the process of identity formation, adolescents establish their own values and belief systems. One such system involves beliefs about how different social groups should relate to each other, inter- and intragroup membership and dynamics and prejudice. The development of prejudice among children has been studied (see Narter, 2006 for a review), yet the

emphasis in nearly all these studies has been on race, ethnicity, and gender (e.g., Bigler \& Liben, 1993; Killen, Lee-Kim, McGlothlin, \& Stangor, 2002; Rutland, Cameron, Milne, \& McGeorge, 2005). In early and middle childhood, race and gender are salient groups that children are easily able to recognize due to physical differences. With increased social comparison and advanced cognitive skills, adolescents recognize more subtle signs that individuals may belong to different groups. For example, certain jewelry might represent certain religious groups and brands of clothing might signal one's socioeconomic status. This heightened awareness of groups in adolescence may lead to increased reflection about intergroup relations and how different groups should be positioned in society. Yet, limited research has examined how children and adolescents develop beliefs and attitudes about group hierarchy and the social contexts that affect those beliefs.

\section{Social Dominance Orientation}

In adults, one general belief structure concerning intergroup awareness is social dominance orientation (SDO), the preference individuals hold for egalitarian or nonegalitarian relationships among social groups (Sidanius \& Pratto, 1999). This 
orientation is an integral component of Sidanius and Pratto's social dominance theory, which is based on the observation that all human societies consist of group-based social hierarchies. In any society, one group is dominant in its control over resources that have positive social value (e.g., food, wealth). Subordinate groups invariably have less of these resources. The dominant group's position is maintained through a complex relationship between members of both groups who share the opinion that the dominant group is justified in their control over these resources. Males, who have historically been dominant in every society, consistently score higher than females on measures of SDO (the invariance hypothesis; Sidanius \& Pratto, 1999). Individual differences in SDO appear to play an important role in intergroup relations.

Individuals who score high on SDO measures indicating their preference for greater inequality among social groups support hierarchy-enhancing (HE) policies and practices, such as funding schools through property taxes. In contrast, individuals who scored lower on measures of SDO and prefer less inequality among social groups would support hierarchy-attenuating (HA) policies and practices such as social welfare programs for the poor. Based on social dominance theory, stability exists in societies where these opposing forces are in balance and "the degree of group-based social hierarchy has yet to become either morally offensive or structurally destabilizing" (Sidanius \& Pratto, 1999, p. 51-52). With social stability at stake, it is imperative that we learn more about the development of this preference for inequality.

Individuals who are opposed to group equality are reported to believe that the world is a "competitive jungle in which power, toughness, machismo, defence of one's honor, and dominance become important values and goals" (Duckitt, 2001, p. 92). SDO scores 
in adults correlate with anti-Black and homosexual prejudice (Whitley, 1999), to proingroup and anti-minority attitudes (Duckitt, 2001), and to generalized prejudice (Ekehammar, Akrami, Gylje, \& Zakrisson, 2004). Discrimination that results from SDO is related to a desire to maintain inequality between dominant and subordinate groups without an emphasis on characteristics related to specific groups. As such, SDO is a general knowledge structure about one's beliefs related to social hierarchy (i.e., some groups should have higher status than others) as opposed to more specific beliefs about certain groups (i.e., stereotypes). In a longitudinal study of college freshman through their senior year, Sidanius, Sinclair and Pratto (2006) found a significant reduction in SDO scores between subjects' first and last year, suggesting that this attitude can be shaped over time. As they develop their knowledge base about social functioning and stability, adolescents are likely to be simultaneously developing a preference for group equality.

The SDO construct has been studied extensively in adults (e.g., Duckitt, 2001; Jost \& Thompson, 2000, Whitley, 1999), but there has been less research conducted with adolescents (Chazal \& Guimond, 2003; Duriez \& Soenens, 2006; Huang \& Liu, 2005; Poteat, et al., 2007). Duriez and colleagues (Duriez, Soenens \& Vansteenkiste, 2008) found extrinsic goal orientation, a preference to pursue such external goals as wealth, social recognition and physical attractiveness, to be a mediating factor in the concordance between parents' and adolescent's SDO scores. In a sample of $7^{\text {th }}$ to $11^{\text {th }}$ graders, SDO scores became more similar in a friendship network over time (Poteat et al., 2007).

Despite these efforts, the paucity of research in this area suggests that there is still much to learn about how social relationships are associated with SDO.

\section{Parenting and SDO}


Although reflecting on commitments to certain values and beliefs such as SDO is largely an internal process, the development of such worldviews takes place in multiple contexts, including family, peers and school (Allison \& Sabatelli, 1988). Thus, we believe that socializing experiences in childhood and adolescence likely influence the development of SDO. There are some clues in the literature with adults to support our belief. Parenting practices referred to as "unaffectionate socialization" were correlated with SDO scores in a study conducted with college students (Duckitt, 2001). This parenting practice parallels the authoritarian style of parenting, characterized by strict rules for their children with little warmth and responsiveness toward them (Baumrind, 1991).

Parental warmth and responsiveness, referred to as an authoritative style, may also be associated with adolescent's SDO. In six different studies, Sidanius and Pratto (1999) found negative correlations with SDO, from -.40 to -.53, in a measure of concern for others (Pratto et al., 1994). Overall empathy measures also correlated negatively, from -.21 to -.40 . The development of empathy and concern for others has been linked to parenting practices. Positive parental responsiveness to a child's distress or to the distress of others promotes empathic responding in children, by helping them to learn how to regulate their own negative feelings towards the distress (Davidov \& Grusec, 2006).

“Responsiveness to distress promotes children's ability to decode accurately others' emotions... which can facilitate empathy" (p. 45). To date, there has been no research that has examined the effects of parenting style on SDO.

\section{Adolescent Crowds}

Although parents certainly affect their children's beliefs and values, adolescent's 
peers are also a source of influence. In fact, crowds, a phenomenon of group formation in adolescence, provide experience with groups of different people who are recognized and vary in social status within the limited arena of schools. Adolescent crowds are defined as peer groups with common characteristics, interests, attitudes, or abilities (Brown, Mory, \& Kinney, 1994). Crowds form to provide predictable social interactions for adolescents; when they can recognize others by the crowd to which they belong, adolescents can assume common or disparate interests or attitudes that help to structure their interactions (Brown et al., 1994; Youniss, McLellan, \& Strouse, 1994).

The literature on adolescent crowds contains a number of different methods of identifying members, each assuming a definition of crowd that may be different from other methods (see Cross \& Fletcher, 2009 for a review), based on either the socialcognitive dimension of crowds - how the society around them is structured - or the identity dimension - how they fit in the society and who they are (Cross, in press). The social-type rating (STR; Brown, 1989; Schwendinger \& Schwendinger, 1985) method defines crowds as reputation-based (social-cognitive dimension). Peers determine one's crowd membership based on their perceptions of the individual's characteristics. Another method of identification groups together individuals based on their behaviors such as athletic participation or academic achievement, or characteristics of dress, music preference and the like. The most frequently used method of identification of crowd membership is self-identification, although the questions asked in this method vary widely. Subjects may be asked "who they 'hang out with,' who they identify with, who they want to be identified with, who others think they are, or a combination of all of these" (Cross \& Fletcher, 2009, p. 756). Each of these requests assumes a different 
definition of crowd membership, suggesting either social-cognitive or identity variants.

Regardless of the lack of consensus in the literature on a definition, nearly every study of adolescent social environments finds distinct crowds such as jocks, populars, and normals. Sussman, Pokhrel, Ashmore and Brown's (2007) review of the literature describes the five general crowd categories found in 44 studies: Elites, Athletes, Deviants, Academics, and Others. Even with these composite descriptions, crowds form somewhat uniquely in response to the social climate of each school and crowd names may differ widely. Adolescent crowds fit the description of arbitrary-set groups, groups based on any socially constructed, highly salient characteristic such as race, social class, or religion, in Sidanius and Pratto's (1999) social dominance theory and, therefore, may be pivotal in the formation of adolescents' preference for inequality among groups.

\section{Crowd Status}

The status of crowds in the social structure of schools has been acknowledged. Although empirical data is absent, we believe that crowd status may be connected to resources of positive social value within schools. Although Kinney (1990) claimed that status is accorded to those with highest visibility (the trendies), one of the most visible groups in the school because of their dramatic appearance, the punkers, was at the bottom of the status hierarchy. Rigsby and McDill (1975) proposed that students vary in their commitment to the formal (grades, honors, "prestige in a sponsored status system designed to give support to the implementation of the formal educational goals of the school," p. 58) or informal ("core values, the social activities, and the well-being... of student life") reward systems in school. The informal reward system emphasizes "visibility, fame, and likely 'success' in the social life of the school" (p. 59). Stone and 
Brown (1998) expanded on this social mapping, relabeling the axes with "academic engagement" (formal reward orientation) and "peer status" (informal reward orientation). Using multidimensional scaling of adolescents' rating of crowd similarity, the crowds are positioned in the quadrant as we might expect from the stereotype each crowd label evokes: high status, high academic orientation - populars; high status, lower academics jocks; lower status, high academic - brains; medium status, lowest academic orientation rebels, and so forth.

Eckert (1989) considers school staff to play the most important role in the status hierarchy:

Ultimate power in the hierarchy resides with the staff, who control the basic resources - materials, space, time, freedom of movement, and sponsorship necessary to produce all activities and to achieve visibility. ... [students] control the important resources of student labor and participation. The students themselves must arrive at positions of power through management of contacts with their peers and with staff. (p. 111)

From this perspective, students who do not cooperate with the school's formal reward system will not share in the resources controlled by staff, and thereby lose status in the school hierarchy. The rebel/headbanger crowd, however, achieved significant status in Kinney's (1990) study, with some headbangers having equal status among peers to the popular "trendies." Hollingshead $(1949,1975)$ claimed that status was directly related to family's SES, but Cohen (1979) found no relationship between SES and crowd status. Schwendinger and Schwendinger (1997) report that "the largest sociometric studies published while Hollingshead's theory enjoyed virtually universal acclaim, without 
exception, contradicted his central proposition about adolescent friendships and parental status" (p. 73).

Although crowd status has been investigated in numerous studies, methods have varied, using interviews or open-ended surveys (e.g., Brady, 2004; Eckert, 1989; Garner, Bootcheck, Lorr \& Rauch, 2006; Kinney, 1990), ranking or ratings of status given no criteria for doing so, relying on respondents' tacit knowledge of crowd status (Brown \& Lohr, 1987; Stone \& Brown, 1998; Stone \& Brown, 1999), or ratings based on other research (La Greca \& Harrison, 2005; McFarland \& Pals, 2005). Despite the problems with this research, we felt that crowd status served as an indirect marker for dominance within the school and thus included crowd status to help explain potential differences in SDO among crowds.

\section{SDO and Discrimination}

The relationship between prejudicial attitudes and discriminatory behavior has been supported by voluminous research (Whitley \& Kite, 2006). Even as prejudices have become less socially acceptable and, therefore, less likely to be expressed or acknowledged, the discriminatory effect of underlying beliefs can still be dramatic, as Dovidio and colleagues (e.g., Dovidio \& Gaertner, 2004; Pearson, Dovidio \& Gaertner, 2009) have shown in their research on aversive racism. The aversive racist believes s/he is not prejudiced, but exhibits behaviors that indicate a preference for avoidance of any interracial interactions and even discriminates in some situations. For example, White subjects high in aversive racism chose a White job candidate over a Black candidate with much greater frequency when both had ambiguous qualifications (Dovidio \& Gaertner, 2000). The relationship between attitudes and behavior is evident in Tajfel's (Tajfel, 
1969; Tajfel, Billig, Bundy, \& Flament, 1971) minimal group paradigm, which has been supported by research (Patterson \& Bigler, 2006) among even preschoolers, who learned their group membership from teacher behaviors and exhibited ingroup biases as a result. SDO, an individual's belief about equality among social groups, correlates with many measures of prejudice (Pratto, Sidanius, Stallworth \& Malle, 1994). Among other negative correlates, high levels of SDO have been associated with unethical decisionmaking (Son Hing, Bobocel, Zanna \& McBride, 2007) and with self-reported bullying and discriminatory behaviors (Parkins, Fishbein \& Ritchey, 2006). Such research points to the importance of understanding not simply individuals' beliefs about group members, but also their beliefs about equality and social structure. The socialization process leading to such beliefs involves parents and peers. The influence of parents on the development of prejudice has been studied (e.g., Rodriguez-Garcia \& Wagner, 2009), but research on the development of social dominance orientation has not yet been done. Similarly, little research has focused on how the school environment in which nearly all U.S. children participate contributes to the development of attitudes about intergroup relations. Adolescent crowds represent minimal groups - arbitrary-set groups according to social dominance theory - in the school setting, suggesting ingroup favoritism and outgroup bias that have not been previously studied. This study is an exploration into the relationships among parenting practices, crowd affiliation and beliefs about intergroup relations.

\section{The Current Study}

To learn about the possible influence of parents and peers on adolescents' SDO, this study sought to answer two research questions: What is the relationship among 
parents' responsiveness (their sensitivity to the child's needs and willingness to react positively and warmly while supporting the child's autonomy) and demandingness (their efforts to behaviorally and psychologically control the child) and their adolescent's level of SDO? What is the relationship among an adolescent's crowd membership, their beliefs about their crowd, and their level of SDO? The first hypothesis was that parents' responsiveness would have an inverse relationship with adolescents' SDO, while demandingness would be positively correlated. The second hypothesis was that adolescents' membership and/or importance of membership in high status crowds would be associated with higher levels of SDO than adolescents' membership and/or importance of membership in low status crowds.

\section{Participants}

\section{Method}

Adolescents in grades $9-12$ in a rural, Midwest high school participated in the study $(N=516)$. The school population of approximately 900 students was not ethnically diverse, with 96\% White, 1\% Multiracial, 1\% Black, 1\% Hispanic, and 1\% Asian. Because of the lack of diversity in the school, students were not asked to identify their ethnicity on the survey. The mean age of respondents was $16.18(S D=1.13)$. The school district had a blanket consent form policy for anonymous surveys, so all students in the school were given the surveys. However, each student was asked to indicate her or his permission to use the survey. In total, 657 students filled out the survey, with 61 indicating they did not wish their survey to be used in this research and 80 giving no response to the request. Students who did not give permission to use their data were similar to the final sample of students, with approximately equal numbers of students 
declining in each grade and equal numbers of females (48\%) and males (52\%). Five hundred and sixteen students indicated their permission on the survey but 14 students did not provide complete demographic information. The demographic information for the 502 students is presented in Table 1.

\section{Procedure}

To obtain crowd names used in the school, the researcher provided a lecture on adolescent crowds, during which students named the crowds they were familiar with in the school. School officials identified classes that could be used for these lectures, thus the four lectures were given to approximately 90 ninth graders in a required health class and 7 twelfth graders in an advanced psychology class. In the different classes, students mentioned 31 crowd names or versions of the same crowd name (e.g., farmer/ redneck/ cowboy/ hick). To reduce this list to the most recognizable crowds in the school, only names used by students in both grades or by 3 out of the 4 classes were included on the survey. Because of substantial evidence in the literature that many students identify themselves as being in the "Normal" crowd (e.g., McFarland \& Pals, 2005; Sussman, et al., 2000; Urberg, 1992), the "Normal" crowd was retained, even though it was mentioned by only one class. This reduction resulted in 10 crowd names to be included on the survey: Jocks/Athletes, Preps, Scenesters/Scene Kids/Emo, Farmers, Smart Kids/Nerds, Stoners/Druggies, Goths/Gothics, Skater/Punks, Band Kids/Musicians/Choir, and Normals.

During one class period (50 minutes) in the spring semester, survey packets, including a letter from the principal informing students that their participation was voluntary and a list of teacher instructions, were distributed to all classes $(N=40)$. Each 
packet contained the principal's letter along with the instruments in the following order:

SDO, demographics and activities, crowd status rankings, parental

demandingness/responsiveness and crowd affiliation. Students placed completed

anonymous surveys in sealed boxes. At the end of the class period, the researcher removed all boxes and data from the school.

\section{Measures}

Social dominance orientation. The first instrument in the survey packet was the SDO scale, to avoid any priming effect of demographic questions or crowd ratings or affiliation. Subjects received the Jost and Thompson (2000) SDO scale, which was developed from the Pratto, et al. (1994) 16-item instrument to enhance the two factors, opposition to equality (OEQ; e.g., "All groups should be given an equal chance in life.”) and group-based domination (GBD; e.g., "If certain groups of people stayed in their place, we would have fewer problems."). Scale reliability was adequate for the Jost and Thompson SDO scale with this sample, Cronbach's alpha $=.88$.

Higher scores on the 7-item Likert scale from strongly disagree (1) to strongly agree (7) indicate a stronger preference for group-based domination and/or opposition to equality. Although a strongly agree would be a score of 7, research on SDO has reported that there is skewness toward the strongly disagree for all respondents. For example, in their report of 39 studies, the average mean reported was 2.6 with a standard deviation of .79 on a 7 -point scale. Although only items above 4 indicate true agreement with the dominance-oriented statement, researchers look upon relative differences in the lower distribution as meaningful (Sidanius \& Pratto, 1999). 
Demographics. Subjects were asked to report their gender, age, and grade.

Extracurricular activities in which students participate were also collected but were not examined in the current study.

Crowd status. To indicate students' perceptions of their own crowd(s) and other crowds in the school, subjects were asked to categorize the status of each crowd from the list of crowd names. Students responded to the comment "At High School, this crowd has..." by checking a box for highest, high, medium, low, or lowest status beside the crowd name. Consistent with other studies that relied on respondents tacit knowledge of crowd status (Brown \& Lohr, 1987; Stone \& Brown, 1998; Stone \& Brown, 1999), no definition of "status" was provided. An average crowd status for the full sample was determined by aggregating responses for each crowd. Subjects were allowed to write in another crowd (or crowds), but very few subjects chose to do so.

Parental behaviors. Parental behaviors were assessed using a parental demandingness/ responsiveness instrument (Paulson, 1994) that allowed students to give their own perceptions of parental behavior. Their perceptions of behavior were deemed more important to the development of their SDO than actual parent behaviors. This scale was selected because of its emphasis on responsiveness and its appropriateness for the adolescents. To avoid the confusion of identifying "parents," students were asked to respond by circling the option "that best describes the person you most closely identify as your MOTHER [FATHER].” Questions from both scales were randomly intermingled for the mother and appeared in the same sequence for the father. Students were asked to respond on a scale of 1 (Very Unlike) to 5 (Very Like) to such demandingness questions as "I think my mother [father] disciplines me a lot" "My mother [father] usually wants to 
know where I am going" "My mother [father] gives me a lot of freedom" and such responsiveness questions as "My mother [father] takes an interest in my activities" "My mother [father] encourages me to talk to her [him] honestly" "My mother [father] usually tells me the reasons for rules." With this sample, reliability was consistent for the two scales: both mother's and father's demandingness scales had an $\alpha=.85$ and both responsiveness scales had an $\alpha=.86$.

Crowd affiliation. Self-identification of crowd membership was considered most appropriate to this study of respondents' worldview. The crowd to which subjects believed they belonged was more important in this analysis than others' beliefs about their membership. Students were asked to "please indicate the one(s) to which you consider yourself to belong. Choose as many as apply to you.". Ten crowd names were included in the survey: Jocks/Athletes, Preps, Scenesters/Scene Kids/Emo, Farmers, Smart Kids/Nerds, Stoners/Druggies, Goths/Gothics, Skater/Punks, Band Kids/Musicians/Choir, and Normals. Students could claim membership in as many crowds as they considered appropriate.

Although the reduction of the list of available crowd names to those most frequently named during the class lectures could have resulted in many students not finding "their" crowd on the list, subjects could write in any crowd names not listed. Surprisingly, very few respondents added any crowd names to the list. Fifteen percent $(n=77)$ of students added crowd names for status ranking, and 9\% $(n=47)$ to claim membership in a crowd not on the list. In addition to their crowd affiliation, subjects were also asked to rate the importance of crowd membership to them. For each crowd on the list, students were asked to indicate membership (Are you a member of this crowd? 
Yes/No) and importance (Belonging to this crowd is extremely/somewhat/not at all important to me). Following the list of named crowds, subjects were asked to "Add any other crowds that you consider yourself to belong to." Subjects were next asked to respond to the statement, "I believe I belong to this crowd more than any other: (Please circle only one)." They could also enter crowds not listed for this question. This allowed assignment to just one crowd for comparisons between members of high and low status crowds, while maintaining information about subjects who were members of multiple crowds.

Missing Data. A number of participants filled out one or more of the scales on the survey with the same response (i.e., all 1's, all 3's, etc.). Because the scales each had some reverse-coded items, such responses indicated that the students were not considering the survey questions. Those scales with all the same responses were converted to missing items, thereby excluding them from further analysis. This elimination resulted in missing data for 4 SDO scales, 6 mother and 31 father scales, both responsiveness and demandingness.

\section{Results}

\section{Gender and Grade}

Univariate ANOVA was used to determine statistically significant differences between males and females in SDO for the full sample. SDO scores were significantly different for males and females, $F(1,478)=37.7, p<.001, \eta^{2}=.07$. All comparisons of SDO included gender, which was entered in hierarchical regression analyses to account for gender differences or as an independent variable in ANOVAs to examine potential interactions with gender. Students with more years of schooling (i.e., grade 12) did not 
differ in SDO from students with fewer years in school, $F(3,488)=.07, p=.977$. SDO scores were not statistically different by grade.

\section{Parenting and SDO}

Mean SDO scores and adolescents' perceptions of their parent's responsiveness and demandingness are reported in Table 2. SDO was negatively correlated with mother's responsiveness $(r=-.17, p<.001)$ and demandingness $(r=-.14, p<.01)$ and with father's responsiveness $(r=-.15, p<.01)$. Adolescents who believed that their parents were more responsive had lower SDO scores. Contrary to expectations, when adolescents reported their mothers were more demanding, they had lower SDO scores. The father's demandingness was not related to SDO.

The test of correlations was followed by hierarchical regression (Table 3), entering gender, then mother's and father's responsiveness and demandingness on the dependent variable of adolescent's SDO score. Both mother's $(\beta=-.15, p<.01)$ and father's responsiveness $(\beta=-.12, p<.05)$ significantly predicted adolescent's SDO scores after controlling for gender. Parents' demandingness did not contribute significantly to the variance in SDO. Parents' responsiveness explained 4\% of the variance in SDO scores.

\section{Multiple Affiliations}

Membership was determined in response to the statement "I am a member of this crowd." Students could respond "Yes" or "No" to this statement, but several students $(n=21)$ chose both or quite deliberately marked directly on the line between the two. These students were considered "Somewhat" members of the crowd. Students could claim membership in any or all of the 10 listed crowds or they could enter the name of 
other crowds not listed. Forty-seven students claimed membership in one of these selfnamed crowds. The only potential for a crowd with a membership larger than two was a religious crowd, mentioned by only four students. Because of the low numbers of students naming their own crowds, this data was not analyzed.

The majority of students $(76 \%)$ claimed membership in more than one crowd. The most frequent single crowd named was Normals (42\%), with Jocks (17\%) a distant second. The number of students with a single crowd membership of Normals masked the variety of crowds in which they actually considered themselves to be a member. The very small cell sizes in some crowds (i.e., Goths, Farmers) compromised the results of statistical analyses. This presented a problem for a study of individuals' SDO. An analysis of the crowds, but not the individuals who claim membership, would not provide a picture of adolescents' SDO. Because of the emphasis on the individual as the unit of analysis in this study, cluster analysis provided an option for analyzing individuals who were similar in their patterns of membership.

Cluster analysis is recommended for grouping data into "relatively homogenous" sets based on similarity of selected variables (Gore, 2000). Although it is often used to reduce the number of categories of data, our purpose in this study was to identify patterns of crowd membership that would achieve independent samples for comparison of the independent variables. Cluster analysis determines the mathematical proximity of cases and groups together those with the closest proximity of the selected variables. In this study, the variables of interest were those indicating category of membership (yes, no, or somewhat) in each crowd (i.e., Jock, Prep, Emo, etc.). Because these variables were categorical, the distance measure between cases was log-likelihood, a probability 
distribution of the variables rather than their Euclidean distance. The appropriate method for clustering categorical data is the two-step cluster analysis (Garson, 2008). Gore (2000) suggests that, in the absence of accepted statistical methods, the number of clusters to interpret is best determined by "theoretical rationale" or "subjective inspection." The usual "stopping rules" for determining the appropriate number of clusters do not apply when analyzing categorical versus continuous data. The specification of an 8-cluster solution produced clusters that were readily recognizable as heterogeneous in their composition (Hair, Black, Babin, Anderson, \& Tatham, 2006) and relatively homogeneous in the number of members. Thus cluster analysis was used to determine "crowd cluster" membership, with each student placed into a particular cluster based on his/her patterns of crowd affiliation.

Table 4 describes the crowd memberships of students in each cluster. The number who indicated "Somewhat" membership in a crowd is indicated in Table 3 as a subscript to the number who chose "Yes". The first cluster, Just Normals, includes members who chose only Normals as their crowd. Most Jocks and most Preps were found in the Preppy Jock cluster. The Edge Folk were so named because they exist outside of mainstream culture. The Emo, Punk, Goth and Druggies were mainly found in this cluster. More than half of the Edge Folk considered themselves to be Normals as well. The majority of Band Kids were found in the Smart Band Kids cluster. Many of these students also considered themselves to be in the Smart/Nerd crowd. None of the 54 members of the Aloof Kids cluster considered themselves to be Normals. Several of these students did not claim membership in any crowd at all. This is the opposite of the All-Around Kids (a name suggested by the findings of Strouse, 1999 and Youniss et al., 2001), most of whom 
chose more than one crowd. Nearly all the Rural cluster members were Farmers and many were Jocks or Preps. The second-highest number of Druggies $(n=13)$ was found in the Rural cluster. All members of the Smart Normals considered themselves part of the Smart/Nerd crowd and Normals. Many members of this cluster were also Jocks.

One purpose in examining crowd membership was to determine if the named crowds were part of a social hierarchy in the school that might affect student's SDO. Table 5 describes the mean status rankings for the full sample. The Druggie crowd had the greatest variability in status ratings, with a standard deviation of 1.27. The variability of other status ratings in this sample was relatively low, indicating that students agreed which crowds were on top and which crowds were on the lower end of the social hierarchy.

To explore the relationship between crowd membership and SDO, univariate ANOVA was conducted with crowd cluster membership and gender as the independent variables and SDO as the dependent variable. Table 6 contains SDO means for each cluster. There was a significant interaction with gender, $F(7,464)=2.36, p<.001$, $\eta^{2}=.044$, and main effect of crowd cluster, $F(7,464)=4.73, p<.001, \eta^{2}=.061$. A further analysis of the interaction identified that females in the different clusters did not have a significant difference in SDO scores, $F(7,249)=1.29, p>.05$, but males did, $F(7$, $215)=5.07, p<.001, \eta^{2}=.14$.

To identify the source of differences between SDO scores among males, a univariate ANOVA and a Tukey post-hoc comparison were executed using an alpha level of .017. Among males, the Preppy Jock cluster $(M=3.74, S D=.77)$ differed significantly from the Smart Band Kids $(M=2.67, S D=.84)$ and the Rurals $(M=3.82, S D=.92)$ differed 
significantly from both the Smart Band Kids $(M=2.67, S D=.84)$ and the All-Around Kids $(M=2.80, S D=.98)$.

\section{Crowd Affiliation and Importance}

A second technique was implemented to analyze the crowd membership and crowd importance data using a variable-centered approach. For this analysis, we returned to the data about crowd affiliation in the 10 most common crowds as opposed to the eight groups of multiple crowd membership from the cluster analysis. An index was created for each of the crowds, multiplying crowd membership (Yes $=1$, No $=0)$ by crowd importance $($ Extremely=3, Somewhat $=2$, Not at All Important $=1)$. Along with gender, this crowd index was entered into a multiple hierarchical regression using the full dataset to determine its relation to SDO. A number of significant predictors of SDO were found at an alpha level of .05 (see Table 7). The Jocks, Preps, Farmers, and Druggies who reported increased importance of their crowd membership had increased SDO scores. In contrast, Smart/Nerds who reported increased importance of belonging to this crowd had decreased SDO scores.

\section{Discussion}

Social dominance orientation, a preference for inequality among social groups, has proven to be an important construct in the study of prejudice. Despite an abundance of studies, little research has focused on the development of this preference. Cognitive advances in adolescents likely lead to the development of more subtle attitudes and beliefs regarding social groups. Rigid beliefs about SDO related to crowds in schools, combined with unequal distributions of resources to students, have the potential to negatively impact school climate. According to Pratto et al. (1994), "social structures and 
policies that prevent the formation of close relationships and empathy between high- and low-status persons (e.g., economically or legally enforced segregation, language barriers, publishing biases), would seem to discourage empathy between groups and the formation of a common identity.” (p. 757). Tensions among crowds may be a factor leading to decreased students' engagement with their school, and ultimately, decrease student motivation and academic achievement (Eccles, 2007). In order to understand the construct more fully and to begin to combat its negative correlates, the factors that affect its development must be explored. The present study provides evidence that SDO is associated with parents' responsiveness and adolescent crowd membership.

As expected, both mother's and father's responsiveness had a negative relationship with SDO. In addition to the many positive outcomes associated with responsive parenting, such as high social competence and positive self-perception (Baumrind, 1991; Davidov \& Grusec, 2006; Lamborn et al., 1991), we could expect that children of responsive parents will prefer egalitarian relationships among groups in society. Given the connection that has been drawn between parent responsiveness and empathy (Davidov \& Grusec), these findings hint at support for Sidanius and Pratto's (1999) belief that 'the greater one's empathy, the lower one's level of SDO” (p. 49). However, future research is needed to more directly investigate the link between the development of empathy and SDO in children and adolescents.

This study provides the first look into a relationship between adolescent crowds and members' SDO. Evidence in the crowd literature that adolescents may affiliate with multiple crowds was the basis for allowing students to claim membership (Dolcini \& Adler, 1994; Schwendinger \& Schwendinger, 1985; Youniss et al., 1994). In one study, 
209 of 905 adolescents reported identifications with two groups and 93 reported three or more (Youniss et al., 1994). Peers often cannot agree on their classmates' crowd membership (Brown, Mounts, Lamborn \& Steinberg, 1993), suggesting the likelihood of multiple crowd memberships. The overwhelming number of students in this study claiming membership in more than one crowd is a significant finding in itself.

Because of the large numbers of students identified with multiple crowds, cluster analysis was adopted as a way to examine patterns of membership for each student. Because this is a novel approach in crowd research, it is difficult to predict how these clusters may be replicated in other schools. The clusters do, however, mirror the general five types of crowds suggested by Sussman et al.'s (2007) review. More than half of the students in the All-Around, Smart Band, and Smart Normal clusters considered themselves in the Smart/Nerd crowd or what Sussman identifies as the Academics. The Elites and Athletes are represented by the Preppy Jocks, who did not consider themselves only preps or jocks, but were both. The Edge Folk are the Deviants, who might have identified themselves as only Normals if given only one option for crowd membership. The Just Normals and the Aloof Kids could be considered the Others; those adolescents who do not consider themselves a part of one of the other crowd types. Rurals are a crowd specific to the school's rural, farming community. The advantage to the cluster analysis is in identifying those adolescents who consider themselves more than simply an Academic, Deviant, Elite or Athletic. There are Emos and Goths in the All-Around Kids; they also consider themselves Smart and Normal. Through the cluster analysis, we are able to gain a more nuanced perspective of crowd membership than otherwise possible. Other crowd researchers have also begun to investigate new methodologies and statistical 
methods to classify adolescent crowds. For example, Delsing, ter Bogt, Engels and Meeus (2007) utilized factor analysis of crowd affiliation to identify four crowdidentification dimensions; La Greca, Landoll and Lai (2010) allowed subjects to indicate degree of identification with crowds; while Van Zalk and Kerr (2010) grouped adolescents by radical versus nonradical crowd types for comparison.

In this study, females in different crowd clusters did not have significantly different SDO scores from one another. Not only did males have higher scores than females overall, as predicted by the invariance hypothesis, there was also significant variability among their male peers based on the combination of crowds to which they belonged. Although females in the Rural cluster did not have different SDO scores from females in the Smart Band Kids, males in the same clusters differed dramatically in their preference for inequality.

The difference in SDO among males in crowd clusters, but not females, may be associated with natural processes of deyelopment. Adolescence is a time of gender intensification (Galambos, Almeida, \& Peterson, 1990), when "behavioral, attitudinal, and psychological differences between adolescent boys and girls increase with age and are the result of increased socialization pressures to conform to traditional masculine and feminine sex roles" (p. 1905). These pressures to conform encourage boys to be more assertive by expressing their independence, being more physical and more competitive, while girls are encouraged to be more affiliative through their sensitivity, responsiveness and exclusivity in their attentions (Leaper \& Friedman, 2007).

According to the literature (Eisenberg \& Morris, 2004), adolescent females display higher levels of prosocial behavior than males. As adolescent males intensify 
their efforts to become more masculine (Galambos et al., 1990), their sympathy for others does not increase at the same rate as their female counterparts. In fact, a study of male and female sympathetic concern for others found that male sympathy for a female target went up, but sympathy with a male target went down with age, particularly between grades 8 and 9 (Olweus \& Endresen, 1998).

Alternatively, social dominance theory would suggest that those who benefit most from the social hierarchy have the greatest incentive to maintain it, and should, therefore, have the highest SDO. Status is emblematic of control over the objects of positive social value, even if researchers are uncertain what objects are involved. Average crowd status (see Table 5) in this sample was consistent with that found in other research (Sussman et al., 2007), with Preps, Jocks and Normals having high status, and Band Kids, Emos and Goths low status. The status of crowds in the social hierarchy of schools is not well understood. The elements that contribute to status have not been identified. Social dominance theory (Sidanius \& Pratto, 1999) would propose that these unidentified elements are the resources of positive social value that crowds dominant in the school control. An understanding of how we can ascertain dominant crowds in the school through the valued resources they control will benefit studies of SDO as well as those regarding social climate and social cognition.

Although our findings suggest many future directions, there were also limitations that need to be addressed in future research. This study was limited by the difficulties of conducting research in the schools. For example, only $9^{\text {th }}$ and $12^{\text {th }}$ graders were made available for the first phase of the study in which crowd names were solicited. The similarity of crowd names given in both groups indicated that the most frequently named 
crowds were representative of crowds in the school. However, certainly not all crowds were represented on our survey. Cluster analysis has not been previously utilized in crowd research and therefore the clusters may not be replicated in other samples. And although this sample was very similar to the typical samples found in other adolescent crowd research, primarily white, middle-class, these crowds are not likely representative of crowds in more diverse schools (Brown, Herman, Hamm, \& Heck, 2008; HopmeyerGorman, Brown, Kim \& Wax, 2010).

The adolescent crowd research has only begun to intersect the prejudice research with studies such as this one. Adolescent crowds may have a powerful effect on the tolerance or intolerance of differences. Crowds may be an early opportunity for adolescents to practice ingroup favoritism and outgroup bias. As the research on SDO has shown, prejudice exists beyond the traditionally studied realms of race, gender, and ethnicity. It is evident from the findings of this study that there are associations among perceived parent behavior, crowd affiliation and adolescents' preference for equality among social groups.

Despite their ubiquity in the American experience, the powerful social environments of schools have been largely ignored in studies of prejudice. Many have felt minor prejudices in their lives, but these pale in comparison to the experience of those who are racially different or who have different ethnic or religious heritage from the majority. Discrimination against these readily identifiable groups can be seen and calculated. When the differences are more subtle, as in the case of adolescents of the same age who may differ primarily cognitively, in their interests and commitments to learning, sports, extracurricular activities, fashion, or friends, it is harder to gauge 
potential discrimination. Such discrimination based on crowds in schools, either by peers or adults, may lead to an unconstructive atmosphere for learning and impact student academic achievement. It is our hope that this research will encourage others to explore the harsh social terrain of secondary schools that may be fostering a preference for inequality. 


\section{References}

Allison, M.D., \& Sabatelli, R. M. (1988). Differentiation and individuation as mediators of identity and intimacy in adolescence. Journal of Adolescent Research, 3(1), 116.

Baumrind, D. (1991). The influence of parenting style on adolescent competence and substance abuse. Journal of Early Adolescence, 11 (1), 56-95.

Bigler, R. S., \& Liben, L. S. (1993). A cognitive-developmental approach to racial stereotyping and reconstructive memory in Euro-American children. Child Development, 64, 1507-1518.

Brady, P. (2004). Jocks, teckers, and nerds: The role of the adolescent peer group in the formation and maintenance of secondary school institutional culture. Discourse: Studies in the Cultural Politics of Education, 25(3), 351-364.

Brown, B. B. (1989). Social Type Ratings Interview Manual. Retrieved from http://prsg.education.wisc.edu/Measures.html\#m3

Brown, B. B., Herman, M., Hamm, J. V., \& Heck, D. J. (2008). Ethnicity and image: Correlates of crowd affiliation among ethnic minority youth. Child Development, $79,529-546$.

Brown, B. B., \& Lohr, M. J. (1987). Peer-group affiliation and adolescent self-esteem:

An integration of ego-identity and symbolic-interaction theories. Journal of Personality and Social Psychology, 52, 47-55.

Brown, B. B., Mory, M. S., \& Kinney, D. (1994). Casting adolescent crowds in a relational perspective: Caricature, channel, and context. In R. Montemayor, G. R. 
Adams, \& T. P. Gullotta (Eds.) Personal relationships during adolescence (pp. 123-166). Thousand Oaks, CA: Sage.

Brown, B. B., Mounts, N., Lamborn, S. D., \& Steinberg, L. (1993). Parenting practices and peer group affiliation. Child Development, 64, 467-482.

Chazal, S., \& Guimond, S. (2003). La theorie de la dominance sociale et les choix d'orientation scolaire et de roles sociaux des filles et des garcons / Social dominance theory and the choices of academic orientations and social roles among girls and boys. Orientation-Scolaire-et-Professionnelle, 32(4), 595-616.

Cohen, J. (1979). High school subcultures and the adult world. Adolescence, 55, 491-502.

Cross, J. R. (in press). Crowds. In R. J. R. Levesque (Ed.) Encyclopedia of Adolescence. New York: Springer.

Cross, J. R., \& Fletcher, K. L. (2009). The challenge of adolescent crowd research: Defining the crowd. Journal of Youth and Adolescence, 38, 747-764.

Davidov, M., \& Grusec, J. E. (2006). Untangling the links of parental responsiveness to distress and warmth to child outcomes. Child Development, 77(1), 44-58.

Delsing, M. J. M. H., ter Bogt, T. F. M., Engels, R. C. M. E., \& Meeus, W. H. J. (2007). Adolescents' peer crowd identification in the Netherlands: Structure and associations with problem behaviors. Journal of Research on Adolescents, 17(2), 467-480.

Dolcini, M. M., \& Adler, N. E. (1994). Perceived competencies, peer group affiliation, and risk behavior among early adolescents. Health Psychology 13(6), 496-506.

Dovidio, J. F., \& Gaertner, S. L. (2000). Aversive racism and selection decisions: 1998 and 1999. Psychological Science, 11, 315-319. 
Dovidio, J. F., \& Gaertner, S. L. (2004). Aversive racism. In M. P. Zanna (Ed.) Advances in experimental social psychology, vol. 36 (pp. 1-52). San Diego, CA: Elsevier Academic Press.

Duckitt, J. (2001). A dual-process cognitive-motivational theory of ideology and prejudice. In M. P. Zanna (Ed.), Advances in experimental social psychology, vol. 33, (pp. 41-113). San Diego, CA: Academic Press.

Duriez, B., \& Soenens, B. (2006). Personality, identity styles and authoritarianism: An integrative study among late adolescents. European Journal of Personality, 20(5), 397-417.

Duriez, B., Soenens, B., Vansteenkiste, M. (2008). The intergenerational transmission of authoritarianism: The mediating role of parental goal promotion. Journal of Research in Personality, 42, 622-642.

Eccles, J. S. (2007). Families, schools, and developing achievement-related motivations and engagement. In J. E. Grusec \& P. D. Hastings, Handbook of socialization: Theory and research (pp. 665-691). New York, NY: Guilford Press.

Eckert, P. (1989). Jocks and burnouts: Social categories and identity in the high school. New York: Teachers College Press.

Eisenberg, N., \& Morris, A. S. (2004). Moral cognitions and prosocial responding in adolescence. In R. M. Lerner \& L. Steinberg (Eds.), Handbook of adolescent psychology (2 $2^{\text {nd }}$ ed.; pp. 155-188). Hoboken, NJ: John Wiley \& Sons.

Ekehammar, B., Akrami, N., Gylje, M., Zakrisson, I. (2004). What matters most to prejudice: Big five personality, social dominance orientation, or right-wing authoritarianism? European Journal of Personality, 18, 463-482. 
Galambos, N. L., Almeida, D. M., \& Peterson, A. C. (1990). Masculinity, femininity, and sex role attitudes in early adolescence: Exploring gender intensification. Child Development, 61, 1905-1914.

Garner, R., Bootcheck, J., Lorr, M., \& Rauch, K. (2006). The adolescent society revisited: Cultures, crowds, climates and status structures in seven secondary schools. Journal of Youth and Adolescence, 35(6), 1023-1035.

Garson, G. D. (2008). Cluster analysis. Retrieved May 3, 2008 from http://www2.chass.ncsu.edu/garson/PA765/cluster.htm

Gore, P. A., Jr. (2000). Cluster Analysis. In H. Tinsley \& S. Brown (Eds.), Handbook of applied multivariate statistics and mathematical modeling. San Diego, CA: Academic Press.

Hair, J. F, Jr., Black, W. C., Babin, B. J., Anderson, R. E., \& Tatham, R. L. (2006). Multivariate data analysis. Upper Saddle River, NJ: Pearson Prentice Hall.

Hollingshead, A. B. (1949). Elmtown's youth: The impact of social class on adolescents. New York: Wiley.

Hollingshead, A. B. (1975). Elmtown's youth and Elmtown revisited (rev. ed.) New York: John Wiley \& Sons.

Hopmeyer-Gorman, A., Brown, B. B., Kim, B., \& Wax, A. (2010, March). Who knows crowd affiliations better? Comparing expert and non-expert ratings. Paper presented at the annual meeting of the Society for Research on Adolescence, Philadelphia, PA.

Huang, L-L., \& Liu, J. H. (2005). Personality and social structural implications of the situational priming of social dominance orientation. Personality \& Individual 
Differences, 38(2), 267-276.

Jost, J. T., \& Thompson, E. P. (2000). Group-based dominance and opposition to equality as independent predictors of self-esteem, ethnocentrism, and social policy attitudes among African Americans and European Americans. Journal of Experimental Social Psychology, 36, 209-232.

Killen, M., Lee-Kim, J., McGlothlin, H., \& Stangor, C. (2002). How children and adolescents evaluate gender and racial exclusion. Monographs of the Society for Research in Child Development, 67(4), vii.

Kinney, David A. (1990). Dweebs, headbangers and trendies: Adolescent identity formation and change within socio-cultural contexts. Unpublished doctoral dissertation, Indiana University, Bloomington.

Kozol, J. (1991). Savage inequalities: Children in America's schools. New York: HarperPerennial.

La Greca, A. M. (2001). Friends or foes? Peer influences on anxiety among children and adolescents. In W. K. Silverman \& P. D. A. Treffers (Eds.), Anxiety disorders in children and adolescents (pp. 159-186.) Cambridge, UK: Cambridge University Press.

La Greca, A. M., \& Harrison, H. M. (2005). Adolescent peer relations, friendships, and romantic relationships: Do they predict social anxiety and depression? Journal of Clinical Child and Adolescent Psychology, 34, 49-61.

La Greca, A. M., Landoll, R. R., \& Lai, B. S. (2010, March). Adolescent peer crowds: Categorical and dimensional approaches. Paper presented at the annual meeting of the Society for Research on Adolescence, Philadelphia, PA. 
La Greca, A. M., Prinstein, M. J., \& Fetter, M. D. (2001). Adolescent peer crowd affiliation: Linkages with health-risk behaviors and close friendships. Journal of Pediatric Psychology, 26(3), 131-143.

Lamborn, S. D., Mounts, N. S., Steinberg, L., \& Dornbusch, S. M. (1991). Patterns of competence and adjustment among adolescents from authoritative, authoritarian, indulgent, and neglectful families. Child Development, 62, 1049-1065.

Leaper, C., \& Friedman, C. K. (2007). The socialization of gender. In J. E. Grusec \& P. D. Hastings (Eds.) Handbook of socialization: Theory and research (pp. 561587). New York: Guilford Press.

Maccoby, E. E., \& Martin, J. A. (1983). Socialization in the context of the family: Parentchild interaction. In P. H. Mussen (Series Ed.), \& E. M. Hetherington (Vol. Ed.), Handbook of child psychology: Socialization, personality and social development (Vol. 4, 4th ed., pp. 1-110). New York: Wiley.

McFarland, D., \& Pals, H. (2005). Motives and contexts of identity change: A case for network effects. Social Psychology Quarterly, 68(4), 289-315.

Narter, D. (2006). The development of prejudice in children. In B. E. Whitley \& M. E. Kite, The psychology of prejudice and discrimination (pp. 260-297). Belmont, CA: Thomson Wadsworth.

Olrich, T. W. (1996). The role of sport in the gender identity development of the adolescent male. Dissertation Abstracts International: Humanities and Social Sciences, 56(11), 4320. 
Olweus, D., \& Endresen, I. M. (1998). The importance of sex-of-stimulus object: Age trends and sex differences in empathic responsiveness. Social Development, 7, 370-388.

Parkins, I. S., Fishbein, H. D., \& Ritchey, P. N. (2006).The influence of personality on workplace bullying and discrimination. Journal of Applied Social Psychology, 36, $2554-2577$.

Paulson, S. E. (1994). Construction and validation of parenting style and parental involvement scales. Unpublished manuscript.

Pearson, A. R., Dovidio, J. F., Gaertner, S. L. (2009). The nature of contemporary prejudice: Insights from aversive racism. Social and Personality Psychology Compass, 3, 314-338.

Poteat, V. P., Espelage, D. L., \& Green, H. D., Jr. (2007). The socialization of dominance: Peer group contextual effects on homophobic and dominance attitudes. Journal of Personality and Social Psychology, 92(6), 1040-1050.

Pratto, F., Sidanius, J., Stallworth, L. M., \& Malle, B. F. (1994). Social dominance orientation: A personality variable predicting social and political attitudes. Journal of Personality and Social Psychology, 67, 741-763.I

Prinstein, M. J., \& Cillessen, A. H. N. (2003). Forms and functions of adolescent peer aggression associated with high levels of peer status. Merrill-Palmer Quarterly, 49(3), 310-342.

Rigsby, L. C., \& McDill, E. L. (1975). Value orientations of high school students. In H. R. Stub (Ed.), The sociology of education: A sourcebook (pp. 53-75). Homewood, IL: Dorsey. 
Rodriguez-Garcia, J. M., \& Wagner, U. (2009). Learning to be prejudiced: A test of unidirectional and bidirectional models of parent-offspring socialization. International Journal of Intercultural Relations, 33, 516-523

Rutland, A., Cameron, L., Milne, A., \& McGeorge, P. (2005). Social norms and selfpresentation: Children's implicit and explicit intergroup attitudes. Child Development, 76(2), 451-466.

Schissel, B. (2000). Boys against girls: The structural and interpersonal dimensions of violent patriarchal culture in the lives of young men. Violence Against Women, 6, 960-986.

Schwendinger, H., \& Schwendinger, J. R. (1985). Adolescent subcultures and delinquency. New York: Praeger.

Sidanius, J. \& Pratto, F. (1999). Social dominance: An intergroup theory of social hierarchy and oppression. Cambridge: Cambridge University Press.

Sidanius, J., Sinclair, S., \& Pratto, F. (2006). Social dominance orientation, gender, and increasing educational exposure. Journal of Applied Social Psychology, 36(7), 1640-1653.

Son Hing, L. S., Bobocel, D. R., Zanna, M. P., \& McBride, M. V. (2007). Authoritarian dynamics and unethical decision making: High social dominance orientation leaders and high right-wing authoritarianism followers. Journal of Personality and Social Psychology, 92, 67-81.

Stone, M. R., \& Brown, B. B. (1998). In the eye of the beholder: Adolescents' perceptions of peer crowd stereotypes. In R. Muuss (Ed.), Adolescent behavior and society: A book of readings (5th ed.; pp. 158-169). Boston : McGraw-Hill. 
Stone, M. R., \& Brown, B. B. (1999). Identity claims and projections: Descriptions of self and crowds in secondary school. New Directions for Child and Adolescent Development, 84, 7-20.

Strouse, D. L. (1999). Adolescent crowd orientations: A social and temporal analysis. New Directions for Child and Adolescent Development, 84, 37-54.

Sussman, S., Dent, C. W., \& McCullar, W. J. (2000). Group self-identification as a prospective predictor of drug use and violence in high-risk youth. Psychology of Addictive Behaviors, 14(2), 192-196.

Sussman, S., Pokhrel, P., Ashmore, R. D., \& Brown, B. B. (2007). Adolescent peer group identification and characteristics: A review of the literature. Addictive Behaviors, $32,1602-1627$.

Tajfel, H. (1969). Cognitive aspects of prejudice. Journal of Social Issues, 25(4), 79-97.

Tajfel, H., Billig, M. G., Bundy, R. P., \& Flament, C. (1971). Social categorization and intergroup behaviour. European Journal of Social Psychology, 1, 149-178.

Urberg, K. A. (1992). Locus of peer influence: Social crowd and best friend. Journal of Youth and Adolescence, 21(4), 439-450.

Urberg, K. A., Degirmencioglu, S. M., Tolson, J. M., \& Halliday-Scher, K. (1995). The structure of adolescent peer networks. Developmental Psychology, 31(4), 540-

\section{7.}

Van Zalk, N. B., \& Kerr, M. (2010, March). Shy punks, goths, and other eye-catching peer crowds: Are they more prone to problem behavior compared to other shy youths? Paper presented at the annual meeting of the Society for Research on Adolescence, Philadelphia, PA. 
Whitley, B. E. (1999). Right-wing authoritarianism, social dominance orientation, and prejudice. Journal of Personality and Social Psychology, 77(1), 126-134.

Whitley, B. E., \& Kite, M. E. (Eds.). (2006). The psychology of prejudice and discrimination. Belmont, CA: Thomson Wadsworth.

Youniss, J., McLellan, J. A., \& Mazer, B. (2001). Voluntary service, peer group orientation, and civic engagement. Journal of Adolescent Research, 16(5), 456468.

Youniss, J., McLellan, J. A., \& Strouse, D. (1994). "We're popular, but we're not snobs": Adolescents describe their crowds. In R. Montemayor, G. R. Adams, \& T. P. Gullotta (Eds.), Personal relationships during adolescence (pp. 101-122).

Thousand Oaks, CA: Sage. 
Table 1

Participant demographics

\begin{tabular}{cccc} 
Grade & $\begin{array}{c}\text { Female } \\
(\% \text { in grade })\end{array}$ & $\begin{array}{c}\text { Male } \\
n(\% \text { in grade })\end{array}$ & $\begin{array}{c}\text { Total } \\
(\% \text { of total })\end{array}$ \\
\hline 9 & $82(58 \%)$ & $60(42 \%)$ & $142(28 \%)$ \\
10 & $83(56 \%)$ & $66(44 \%)$ & $149(30 \%)$ \\
11 & $57(49 \%)$ & $59(51 \%)$ & $116(23 \%)$ \\
12 & $45(47 \%)$ & $50(53 \%)$ & $95(19 \%)$ \\
Total & $267(53 \%)$ & $235(47 \%)$ & $502(100 \%)$ \\
\hline
\end{tabular}


Table 2

Mean Social Dominance Orientation (SDO) and Parenting Scale Scores

\begin{tabular}{c|cccc}
\multicolumn{1}{c}{ Scale } & $N$ & $M(S D)$ & $M(S D)$ & $M(S D)$ \\
\hline $\begin{array}{c}\text { SDO } \\
\text { Mother's }\end{array}$ & 493 & $3.04(1.00)$ & $2.66(.06)$ & $3.29(.08)$ \\
$\begin{array}{c}\text { Responsive } \\
\text { Mother's } \\
\text { Demanding } \\
\text { Father's } \\
\text { Responsive } \\
\text { Father's } \\
\text { Demanding }\end{array}$ & 499 & $3.40(.71)$ & $3.46(.05)$ & $3.36(.05)$ \\
\hline
\end{tabular}


Table 3

Regression Coefficients for Social Dominance Orientation (Dependent Variable) and Parenting Scales

\begin{tabular}{|c|c|c|c|c|c|c|}
\hline & & $\begin{array}{r}\text { Unsta } \\
\text { Coe }\end{array}$ & ized & $\begin{array}{c}\text { Standardized } \\
\text { Coefficients }\end{array}$ & & \\
\hline & & $B$ & $\begin{array}{l}\text { Std. } \\
\text { Error }\end{array}$ & $\beta$ & $t$ & $p$ \\
\hline 1 & (Constant) & 2.23 & .15 & & 14.90 & .000 \\
\hline & Gender & .53 & .10 & .26 & 5.43 & .000 \\
\hline 2 & (Constant) & 4.05 & .41 & & 10.00 & .000 \\
\hline & Gender & .51 & .10 & .25 & 5.31 & .000 \\
\hline & $\begin{array}{l}\text { Mother's } \\
\text { Responsiveness }\end{array}$ & -.21 & .07 & -.15 & -2.97 & .003 \\
\hline & $\begin{array}{l}\text { Mother's } \\
\text { Demandingness }\end{array}$ & -.14 & .07 & -.10 & -1.92 & .056 \\
\hline & $\begin{array}{l}\text { Father's } \\
\text { Responsiveness }\end{array}$ & -.15 & .07 & -.12 & -2.27 & .024 \\
\hline & $\begin{array}{l}\text { Father's } \\
\text { Demandingness }\end{array}$ & -.03 & .07 & -.02 & -.43 & .670 \\
\hline
\end{tabular}


Table 4

Crowd Memberships by Cluster

\begin{tabular}{|c|c|c|c|c|c|c|c|c|}
\hline \multirow[b]{2}{*}{$\begin{array}{l}\text { Crowd } \\
\text { Name }\end{array}$} & \multicolumn{8}{|c|}{ Cluster Name } \\
\hline & $\begin{array}{c}\text { Just } \\
\text { Normals } \\
n=79\end{array}$ & $\begin{array}{c}\text { Preppy } \\
\text { Jocks } \\
n=85\end{array}$ & $\begin{array}{l}\text { Edge } \\
\text { Folk } \\
n=74\end{array}$ & $\begin{array}{l}\text { Smart } \\
\text { Band } \\
\text { Kids } \\
n=57\end{array}$ & $\begin{array}{l}\text { Aloof } \\
\text { Kids } \\
n=54\end{array}$ & $\begin{array}{c}\text { All- } \\
\text { Around } \\
\text { Kids } \\
n=47\end{array}$ & $\begin{array}{l}\text { Rural } \\
n=48\end{array}$ & $\begin{array}{c}\text { Smart } \\
\text { Normals } \\
n=72\end{array}$ \\
\hline Jocks & $0_{1}$ & 70 & 10 & 181 & 18 & 20 & 22 & 39 \\
\hline Prep & 0 & 45 & 21 & 0 & 17 & $15_{3}$ & 13 & 12 \\
\hline Emo & 0 & 0 & $42_{1}$ & 0 & 4 & $10_{1}$ & $0_{1}$ & 1 \\
\hline Farmers & 0 & 0 & 9 & 0 & 0 & 7 & $39_{2}$ & 6 \\
\hline Smart/Nerd & $0_{1}$ & 0 & 9 & 32 & 0 & $41_{3}$ & & 72 \\
\hline Druggie & $\mathrm{O}_{3}$ & 0 & $30_{2}$ & 0 & 1 & 0 & & 4 \\
\hline Goth & 0 & 1 & $28_{1}$ & 0 & 0 & 2 & 0 & 0 \\
\hline Punk & 0 & 0 & $48_{2}$ & 0 & 0 & & 0 & 2 \\
\hline Band & 0 & 0 & 20 & 57 & 3 & 34 & 1 & 0 \\
\hline Normals & 79 & 85 & 47 & 57 & 0 & 21 & 38 & 72 \\
\hline
\end{tabular}

Note. Subscripted numbers indicate "somewhat" membership in that crowd. 
Table 5

Average Status of Crowds - Highest $=5$, Lowest $=1$

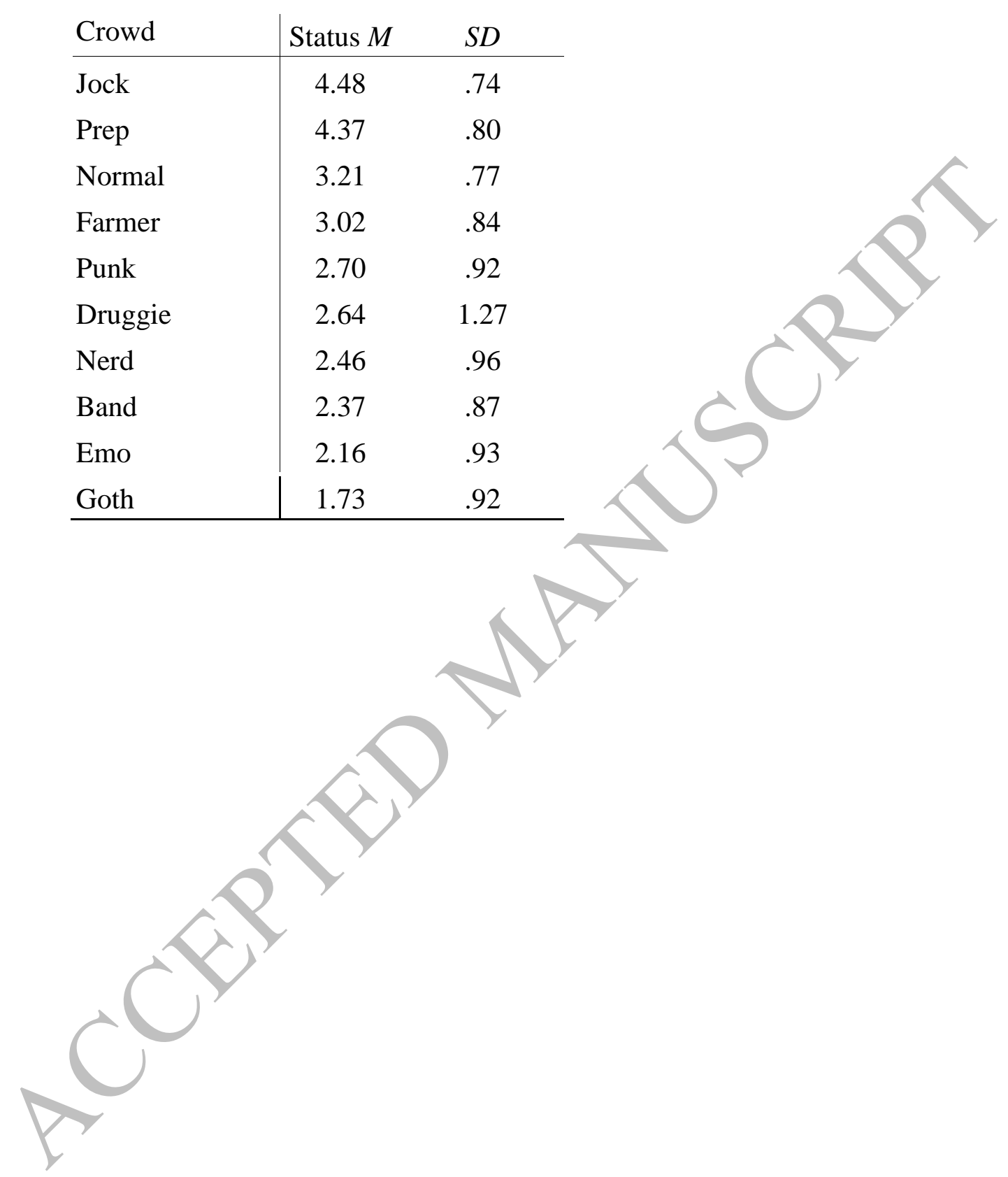


Table 6

Crowd Cluster Social Dominance Orientation Scores

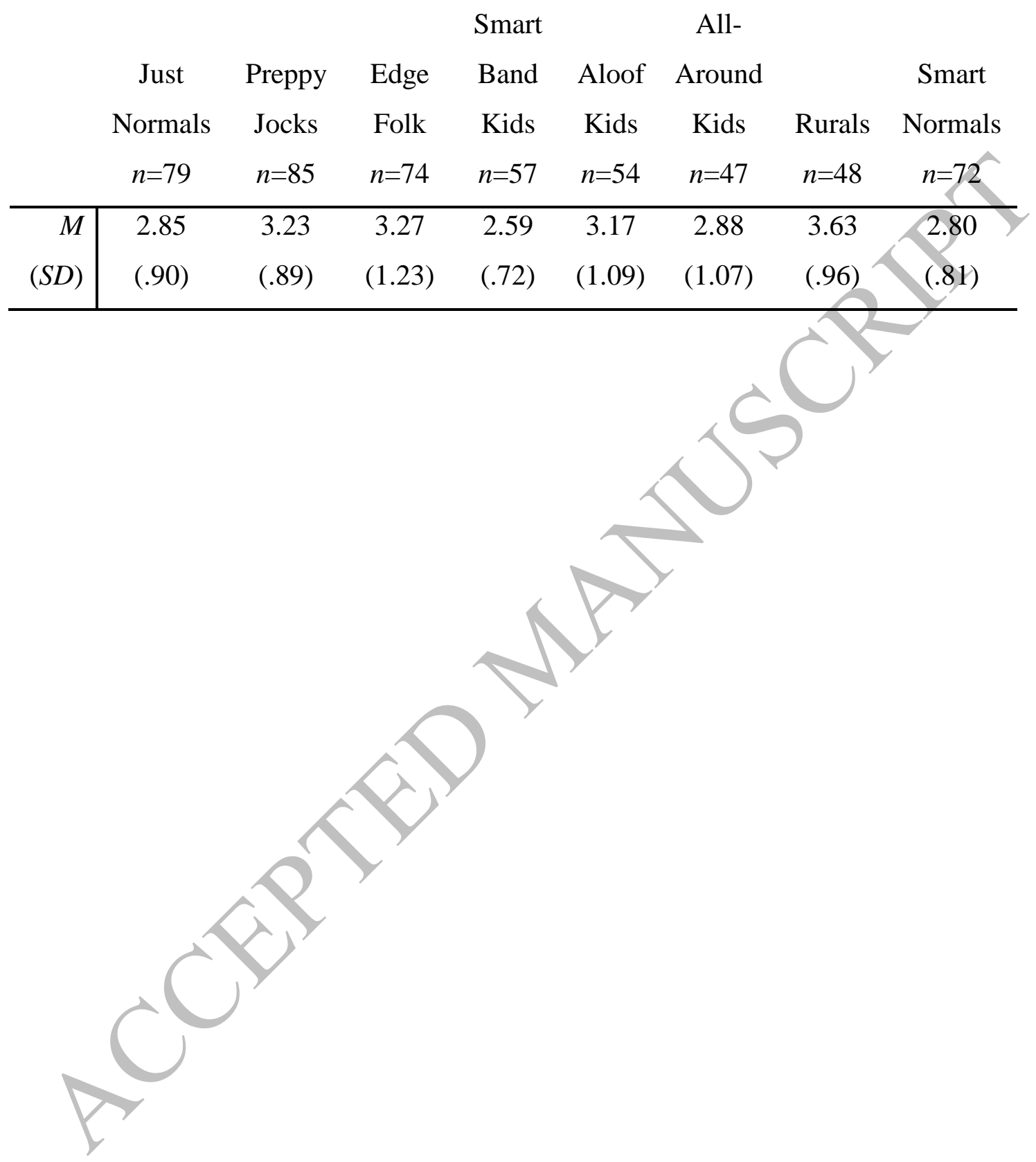


Table 7

Regression of Crowd Index with Social Dominance Orientation ( $\mathrm{N}=406)$

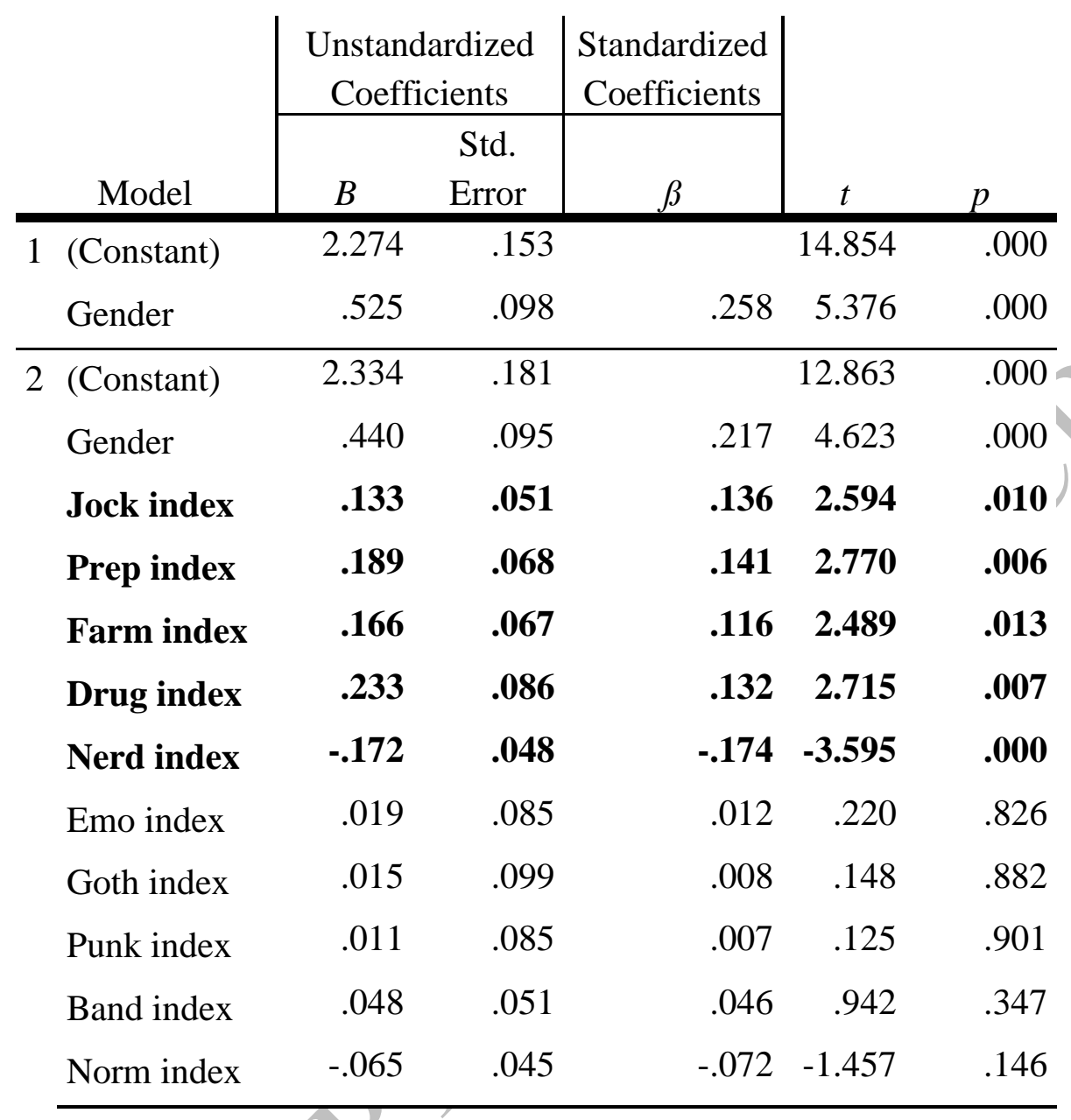

